\title{
The Impact of Substance Use on Treatment as a Compulsory Patient
}

\begin{abstract}
Objective: This paper considers the impact of having a diagnosis of Substance Use Disorder on the utilisation of compulsory orders under the Victorian Mental Health Act (2014).
\end{abstract}

Methods: We analysed the subsequent treatment episodes over two years of people who had been on a Community Treatment Order for at least three months and determined the odds of a further treatment order if there was a diagnosis of substance use at or about the time the index CTO ended.

Results: An additional diagnosis of a substance use disorder was coded in $47.7 \%$ and was associated with significantly increased odds of a subsequent treatment order in the following two years for those with a main diagnosis of schizophrenia $(A O R=3.03, p<0.001)$ and 'other' disorders $(A O R=11.60, p=0.002)$. Those with a main diagnosis of mood disorder had a significant increase in odds for an inpatient treatment order if there was an additional substance use disorder diagnosis $(A O R=3.81, p=0.006)$.

Conclusion: Having an additional diagnosis of substance use disorder was associated with increased likelihood of being placed on an order. This study supports greater emphasis being given to treatment of substance use concurrently with that of mental illness.

\section{Keywords}

Compulsory Treatment; Mental Health legislation; substance use.

\section{Introduction}

Community Treatment Orders (CTO) are widely used, especially in Victoria. ${ }^{1}$ However, there has been limited research on the impact of variables such as comorbid substance use on the effectiveness or otherwise of compulsory care in the community. A recent systematic review and meta-analysis highlighted the complexity of assessing effectiveness of interventions. The authors commented that further work continues to be needed to understand why people do not engage with services, and to promote better community care. ${ }^{2}$ A significant number of persons who present with mental illness have comorbid problems of substance misuse, often with a negative impact on the mental illness in terms of relapse and severity. ${ }^{3,4}$ In this paper we consider the effect of having an additional diagnosis of Substance Use Disorder (SUD) on the subsequent use of state funded mental health services. We used the term SUD to cover the Mental and Behavioural Disorders due to Psychoactive Substance Use (F10 - F19) in ICD-10. ${ }^{5}$

\section{Methods}

Study Design

A data set was obtained from the Victorian Department of Health and Human Services (DHHS). This identified all those who had been on a Community Treatment Order (CTO) of at least 3 months duration at December 2014 and their subsequent service utilisation over two years. We selected the primary diagnosis code in the ICD-10 Mental and Behavioural 
Disorders due to Psychoactive Substance Misuse closest to the time when the index CTO ended.

\section{Data Sources}

The DHHS Victoria administers the Client Management Interface/Operational Data Store (CMI/ODS) system that records all contacts with state funded mental health services. The data set included demographic details, treatment episodes, and the main psychiatric diagnosis as well as additional diagnoses including SUD (and the substance(s) used). The main diagnosis was defined as the diagnosis given at the time of discharge from the index CTO.

\section{Sample}

The data set reviewed included 1297 patients who had been on a CTO for $>3$ months under the Victorian Mental Health Act (2014)(MHA). ${ }^{6}$ Diagnoses of these patients were recorded against ICD-10 codes. Drug induced psychosis was included with other psychoses.

\section{Statistical Analysis}

We conducted three separate time to event analyses looking at factors associated with the time to first: (a)Treatment Order; (b)Community Treatment Order; and (c)Inpatient admission following the conclusion of the patient's index order. A negative binomial regression was conducted in order to assess factors associated with the duration of subsequent orders after the conclusion of the index order.

\section{All analyses were undertaken in Stata version 15.1.}

Ethical approval was obtained from the Melbourne Health Human Research Ethics Committee (No. 2013.109).

\section{$\underline{\text { Results }}$}

An additional diagnosis in the F10-F19 codes (Mental and behavioural disorders due to psychoactive substance use) was recorded in 507 (39.1\%) of patients during the period of the study, with a further $112(8.6 \%)$ having SUD as the most recent diagnosis after the end of the index CTO. That is, significant substance use was recorded in $47.7 \%$. The F1 ICD codes and impact of use are shown in Tables $1 \mathrm{a}$ and $1 \mathrm{~b}$. Alcohol, cannabinoids, stimulants and tobacco were most commonly used - singly or in combination. In the majority, the ICD codes indicated that the use reached threshold for harmful use or dependence $(93 \%)$.

Table 2 shows the distribution of those with and without a SUD and subsequent Treatment Orders. An additional diagnosis of a SUD significantly increased the odds of a subsequent treatment order in the following two years for those with a diagnosis of schizophrenia $(A O R=$ 3.03, $p<0.001)$ and 'other' disorders $(A O R=11.60, p=0.002)$ but not for mood disorders (AOR $=1.95, p=.178$ ) (Table 3 ). This finding related especially to community treatment orders. There was also a significant increase in odds of inpatient admission for those with a diagnosis of a mood disorder with an additional SUD diagnosis compared to those without (AOR $=3.81$, $\mathrm{p}=0.006$ ). The adjusted Cox regression showed that those with comorbid SUD were likely to be placed under an order sooner than those without. This was especially noticeable for CTOs made for patients with schizophrenia and substance use (Table 4).

Those with an additional diagnosis of SUD were not found to have a longer duration of treatment order when controlling for age, sex, index order discharge mode, practice location, primary diagnosis, and time spent on index order 


\section{Discussion}

Substance misuse in psychotic illnesses is common, ${ }^{8-10}$ and is associated with greater risk of relapse and of violence. ${ }^{11}$ There is a greater likelihood of aggressive behaviour in those with schizophrenia who have recently used amphetamines, ${ }^{12}$ and a recent study found that methamphetamine use was associated with a greater likelihood of restrictive interventions such as seclusion and restraint. ${ }^{13}$ In our study, approximately $40 \%$ of those who had been on a CTO for at least 3 months had an additional diagnosis of at least one SUD coded, and needed the provisions of the MHA more often and sooner than those who did not. This is likely to reflect the greater risk of relapse and of behaviour leading to increased risk of harm to others.

There was a difference in the use of CTO and Inpatient Treatment Orders between those who suffered mood disorder, and those with schizophrenia. We found that those with a diagnosis of mood disorder were more likely to require inpatient care; possibly because they are more imminently at risk of harm to self or others and require more urgent and intensive intervention, as opposed to re-stabilisation on treatment, which could occur in the community.

An important consideration with respect to our findings is the current disjunction between Drug and Alcohol services, and clinical mental health services. The lack of clinically led alcohol and drug (AOD) services and the means to compel those who use drugs at harmful levels to accept treatment or remain abstinent has resulted in many AOD services being reluctant to provide services to those with mental illness. This means that for people who have a dual diagnosis and who are reluctant to engage in treatment, it is more likely that they will present to mental health services - often requiring treatment under the MHA, even though the exacerbation of symptoms may be directly related to substance misuse.

One criticism of CTOs has been that they reflect a more medical or biological model of care, rather than addressing some of the other associations of both substance misuse and severe mental illness; such as social isolation, contact with the criminal justice system, poverty and inadequate accommodation. ${ }^{14,15}$ This less than holistic approach is especially likely to occur in the context of constrained mental health services. ${ }^{16,17}$

Our findings support the conclusions reached by Barnett et al that we should focus more on enhancing the quality of community care to strengthen engagement, ${ }^{2}$ in order to reduce the risk of return to harmful substance use and associated relapse of mental illness. In particular, there should be greater integration between mental health and drug and alcohol services with capacity to provide treatment for both types of disorders during the period under the MHA. Such integration would also support more holistic care. 


\section{References}

1. Light E, Kerridge I, Ryan C, Robertson M. Community treatment orders in Australia: rates and patterns of use. Australasian Psychiatry. 2012;20(6):478-82.

2. Barnett P, Matthews H, Lloyd-Evans B, Mackay E, Pilling S, Johnson S. Compulsory community treatment to reduce readmission to hospital and increase engagement with community care in people with mental illness: a systematic review and meta-analysis. The Lancet Psychiatry. 2018.

3. Lepping $\mathrm{P}$, Malik M. Community treatment orders: current practice and a framework to aid clinicians. The Psychiatrist. 2013;37(2):54-7.

4. Menezes PR, Johnson S, Thornicroft G, Marshall J, Prosser D, Bebbington P, et al. Drug and alcohol problems among individuals with severe mental illnesses in South London. The British Journal of Psychiatry. 1996;168(5):612-9.

5. World Health Organization. The ICD-10 classification of mental and behavioural disorders: clinical descriptions and diagnostic guidelines: Geneva: World Health Organization; 1992.

6. Mental Health Act 2014, Victorian Government (2014).

7. StataCorp. Stata Statistical Softwear Release 15. College Station, TX: StataCorp LLC; 2017.

8. Hunt GE, Large MM, Cleary M, Lai HMX, Saunders JB. Prevalence of comorbid substance use in schizophrenia spectrum disorders in community and clinical settings, 1990-2017: Systematic review and meta-analysis. Drug and alcohol dependence. 2018.

9. Buckley PF. Prevalence and consequences of the dual diagnosis of substance abuse and severe mental illness. The Journal of clinical psychiatry. 2006;67:5-9.

10. Buckley PF, Miller BJ, Lehrer DS, Castle DJ. Psychiatric comorbidities and schizophrenia. Schizophrenia bulletin. 2008;35(2):383-402.

11. Swartz MS, Swanson JW, Hiday VA, Borum R, Wagner HR, Burns BJ. Violence and severe mental illness: the effects of substance abuse and nonadherence to medication. American journal of psychiatry. 1998;155(2):226-31.

12. Voce A, McKetin R, Burns R, Castle D, Calabria B. The relationship between illicit amphetamine use and psychiatric symptom profiles in schizophrenia and affective psychoses. Psychiatry research. 2018;265:19-24.

13. McKenna B, McEvedy S, Kelly K, Long B, Anderson J, Dalzell E, et al. Association of methamphetamine use and restrictive interventions in an acute adult inpatient mental health unit: $A$ retrospective cohort study. International journal of mental health nursing. 2017;26(1):49-55.

14. Brophy L, McDermott F. What's driving involuntary treatment in the community? The social, policy, legal and ethical context. Australasian Psychiatry. 2003;11(sup1):S84-S8.

15. Fleischhacker WW, Arango C, Arteel P, Barnes TR, Carpenter W, Duckworth K, et al. Schizophrenia-time to commit to policy change. Schizophrenia bulletin. 2014;40(Suppl 3):S165-S94. 16. Gilburt H. Mental health under pressure. London: The King's Fund. 2015.

17. Vine R, Judd F. Contextual issues in the implementation of mental health legislation. International Journal of Law and Psychiatry. 2018.

\section{Acknowledgements}

The data set was provided by the Department of Health and Human Services, Victoria with the kind assistance of Mr Lachlan Rimes. 
Table 1a. Distribution of F1 ICD-10 diagnosis codes $2^{\text {nd }}$ (Substance type) (619 of total 1297 sample).

\begin{tabular}{|l|l|l|l|}
\hline ICD Code & Substance & Frequency & $\%$ \\
\hline F10 & Alcohol & 104 & 16.8 \\
\hline F11 & Opioids & 36 & 5.8 \\
\hline F12 & Cannabinoids & 150 & 24.2 \\
\hline F13 & Hypnotics & 4 & 0.1 \\
\hline F14 & Cocaine & & \\
\hline F15 & Stimulants (amphetamines) & 79 & 12.7 \\
\hline F16 & Hallucinogens & 1 & \\
\hline F17 & Tobacco & 141 & 22.8 \\
\hline F18 & Volatile Solvents & 1 & \\
\hline F19 & Multiple and Other & 103 & 16.6 \\
\hline TOTAL & & 619 & 100.00 \\
\hline
\end{tabular}

Table 1b. $4^{\text {th }}$ (Impact) Character at end of index CTO

\begin{tabular}{|l|l|l|}
\hline ICD $4^{\text {th }}$ Character & Frequency & $\%$ \\
\hline .0 Acute Intoxication & 21 & 3.4 \\
\hline .1 Harmful Use & 323 & 52.2 \\
\hline .2 Dependence Syndrome & 250 & 40.4 \\
\hline .3 Withdrawal state & 16 & 2.6 \\
\hline .4 Withdrawal with Delirium & & \\
\hline .5 Psychotic Disorder & & \\
\hline .6 Amnestic Syndrome & & \\
\hline .7 Residual/late onset Psychotic & & 1.1 \\
\hline .8 Other disorder & 2 & \\
\hline .9 Unspecified Disorder & 7 & \\
\hline & 619 & \\
\hline
\end{tabular}


Table 2. Association of Substance Use with subsequent Treatment Orders

- $\quad$ SUD = Substance Use Disorder

\begin{tabular}{|c|c|c|c|c|}
\hline \multirow[b]{2}{*}{$\begin{array}{l}\text { Cell key: } \\
\text { n (\%) }\end{array}$} & \multicolumn{3}{|c|}{ Index CTO Discharge Type: n (\%) } & \multirow[b]{2}{*}{ p-value } \\
\hline & $\begin{array}{l}\text { Primary: SUD } \\
\qquad(n=112)\end{array}$ & $\begin{array}{l}\text { Primary without } \\
\text { Secondary SUD }{ }^{a, b} \\
\quad(n=678)\end{array}$ & $\begin{array}{l}\text { Primary with } \\
\text { Secondary SUD } \\
(\mathrm{a}, \mathrm{b}=507)\end{array}$ & \\
\hline \multicolumn{4}{|c|}{ Subsequent Orders within 2 years } & $<0.001$ \\
\hline None & $45(40.2)$ & $431(63.6)$ & $188(37.1)$ & \\
\hline At least one & $67(59.8)$ & $247(36.4)$ & $319(62.9)$ & \\
\hline \multicolumn{4}{|c|}{ Subsequent Community Treatment Orders within 2 years } & $<0.001$ \\
\hline None & $68(60.7)$ & $528(77.9)$ & $320(63.1)$ & \\
\hline At least one & $44(39.3)$ & $150(22.1)$ & $187(36.9)$ & \\
\hline \multicolumn{4}{|c|}{ 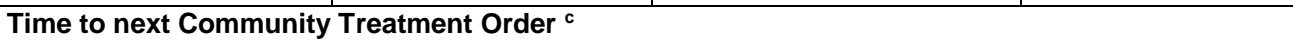 } & 0.707 \\
\hline Up to 180 days & $26(59.1)$ & $90(60.0)$ & $104(55.6)$ & \\
\hline More than 180 days & $18(40.9)$ & $60(40.0)$ & $83(44.4)$ & \\
\hline \multicolumn{4}{|c|}{ Subsequent Inpatient Treatment Orders within 2 years } & $<0.001$ \\
\hline None & $64(57.1)$ & $490(72.3)$ & $242(47.7)$ & \\
\hline At least one & $48(42.9)$ & $188(27.7)$ & $265(52.3)$ & \\
\hline \multicolumn{4}{|c|}{ 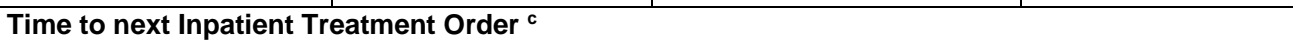 } & 0.606 \\
\hline Up to 180 days & $20(41.7)$ & $82(43.6)$ & $126(47.5)$ & \\
\hline More than 180 days & $28(58.3)$ & $106(56.4)$ & $139(52.5)$ & \\
\hline
\end{tabular}

a) Includes paranoia and acute psychotic disorders including drug induced psychosis

b) Includes those with unknown diagnosis

c) Percentages only for those with subsequent CTO or IPO within 2 years 
Table 3 - AOR for a secondary diagnosis of a Substance Use Disorder, for each primary diagnosis category

\begin{tabular}{|l|l|l|l|}
\hline & Order of any type & Community treatment order & Inpatient admission $^{\text {a }}$ \\
\hline Primary Diagnosis & $\begin{array}{l}\text { Adjusted Odds Ratio }{ }^{\mathrm{b}}(95 \% \\
\mathrm{Cl})\end{array}$ & Adjusted Odds Ratio $^{\mathrm{a}}(95 \% \mathrm{Cl})$ & $\begin{array}{l}\text { Adjusted Odds Ratio }{ }^{\mathrm{a}}(95 \% \\
\mathrm{Cl})\end{array}$ \\
\hline Schizophrenia $^{\mathrm{c}}$ & $3.03(2.30-3.99)$ & $2.31(1.71-3.13)$ & $3.69(2.78-4.90)$ \\
\hline Mood Disorders & $1.95(0.79-4.81)$ & $0.94(0.29-3.07)$ & $3.81(1.48-9.77)$ \\
\hline Other Disorders $^{\mathrm{d}}$ & $11.60(2.48-54.23)$ & $5.39(0.91-32.03)$ & $15.58(3.63-66.85)$ \\
\hline
\end{tabular}

a) With or without an inpatient treatment order

b) Controlling for index CTO discharge method, age at index CTO end, sex, location of mental health service for index CTO (rural/urban), and time spent on index CTO

c) Includes paranoia and acute psychotic disorders including drug induced psychosis

d) Includes those with unknown diagnosis 
Table 4 - Adjusted Cox regression predictors for time to first event in the year following index order end

\begin{tabular}{|c|c|c|c|c|c|c|}
\hline & \multicolumn{2}{|c|}{ Order of any type } & \multicolumn{2}{|c|}{ Community treatment order } & \multicolumn{2}{|c|}{ Inpatient admission $^{\text {a }}$} \\
\hline & $\mathrm{HR}(95 \% \mathrm{Cl})$ & $\begin{array}{c}\mathrm{p}- \\
\text { value }\end{array}$ & $\mathrm{HR}(95 \% \mathrm{Cl})$ & $p$-value & $\mathrm{HR}(95 \% \mathrm{Cl})$ & $\mathrm{p}$-value \\
\hline Primary Diagnosis & & $<0.001$ & & $<0.001$ & & $<0.001$ \\
\hline $\begin{array}{l}\text { Other disorders }{ }^{c} \text { without } \\
\text { secondary SUD }\end{array}$ & 1.00 & & 1.00 & & 1.00 & \\
\hline $\begin{array}{l}\text { Other disorders }{ }^{c} \text { with } \\
\text { secondary SUD }\end{array}$ & $\begin{array}{l}5.11(1.57- \\
16.70)\end{array}$ & & $\begin{array}{l}2.56(0.57- \\
11.53)\end{array}$ & & $8.17(2.90-23.04)$ & \\
\hline $\begin{array}{l}\text { Schizophrenia }{ }^{\mathrm{b}} \text { without } \\
\text { secondary SUD }\end{array}$ & $2.89(1.07-7.79)$ & & $2.39(0.76-7.53)$ & & $2.64(1.09-6.43)$ & \\
\hline $\begin{array}{l}\text { Schizophrenia }{ }^{b} \text { with } \\
\text { secondary SUD }\end{array}$ & $\begin{array}{l}5.51(2.04- \\
14.84)\end{array}$ & & $\begin{array}{l}4.09(1.30- \\
12.89)\end{array}$ & & $5.85(2.41-14.21)$ & \\
\hline $\begin{array}{l}\text { Mood disorders without } \\
\text { secondary SUD }\end{array}$ & $2.48(0.83-7.38)$ & & $1.59(0.43-5.89)$ & & $2.42(0.90-6.51)$ & \\
\hline $\begin{array}{l}\text { Mood disorders with } \\
\text { secondary SUD }\end{array}$ & $\begin{array}{l}4.21(1.38- \\
12.81)\end{array}$ & & $1.34(0.30-6.02)$ & & $5.16(1.92-13.85)$ & \\
\hline SUD & $\begin{array}{c}5.44(1.96- \\
15.06)\end{array}$ & & $\begin{array}{c}4.54(1.40- \\
14.76)\end{array}$ & & $5.842 .34-14.53)$ & \\
\hline
\end{tabular}
(a) With or without an inpatient order
(b) Includes paranoia and acute psychotic disorders
(c) Includes those with unknown diagnosis 